Cadernos de Clio, Curitiba, n. ${ }^{\circ}$ 4, 2013

\title{
TRAJETÓRIA DE UM PATRÍCIO: CONHECENDO RIZKALLAH JORGE TAHAN E A CONSTRUÇÃO DE SEU PODER SIMBÓLICO
}

Renata Geraissati $^{1}$

Resumo: O artigo pretende reconstruir a trajetória de um expoente imigrante sírio-libanês ${ }^{2}$ com ascendência armênia Rizkallah Jorge Tahan (1868-1949), tendo como foco a construção de seu poder simbólico dentro das comunidades que frequentou na cidade de São Paulo. Ao desembarcar no porto de Santos em 1895 fugiu da trajetória da maioria dos imigrantes desta nacionalidade que se tornavam mascates ao chegarem no Brasil. Rizkallah trabalhou com a fundição de cobre, algo que já fazia em sua terra natal. Após três anos na capital paulista inaugurou a Casa da Boia, balcão comercial baseado no comércio de elementos como "a boia sanitária” - o que permitiu seu enriquecimento e, o consequente investimento em uma série de obras nos centros “velho” e "novo” de São Paulo.

Palavras-chave: Rizkallah Jorge, Imigração, Sírio-Libanês, Armênio, Casa da Boia.

${ }^{1}$ Aluna do $8^{\circ}$ semestre de Graduação Bacharelado/Licenciatura em História na Universidade Federal de São Paulo - UNIFESP, contemplada com uma Bolsa de Iniciação Voluntária aprovada pela Comissão Curricular de História - CCH/UNIFESP. Link do Lattes: http://buscatextual.cnpq.br/buscatextual/ visualizacv.do?id=K4365766J5.

${ }^{2}$ O uso da expressão sírio-libanês se dá pelo fato de que até 1926 quando a República do Líbano foi criada, tanto Síria quanto Líbano estavam em um mesmo território, a grande Síria. Como Rizkallah Jorge veio ao Brasil em 1895, sua origem ainda era "turca", pois ainda faziam parte do Império Turco-Otomano, depois da separação passaram a ser denominados sírio-libaneses. Segundo Gattaz, a imigração árabe, a rigor, engloba outras nacionalidades, como egípcios, palestinos, sauditas, iraquianos e outros, porém os libaneses respondem por cerca de 70\% dos imigrantes árabes, no Brasil. 
Cadernos de Clio, Curitiba, n. ${ }^{\circ}$ 4, 2013

\section{Introdução}

A cidade de São Paulo é marcada pela presença de uma enorme diversidade, tanto na fisionomia dos paulistas, como na existência de bairros que são predominantemente habitados por determinadas etnias - como é o caso da Liberdade. Esta interação de diversas etnias é fruto de um processo migratório que trouxe a capital indivíduos das mais variadas partes do mundo. A maior parte da imigração ocorreu entre fins do século XIX e início do XX, momento em que o café já havia trazido uma série de riquezas a cidade de São Paulo e havia propiciado que ela se tornasse central no cenário político brasileiro.

O incentivo à imigração se deu por um projeto de branqueamento da nação, a autora Paula Beiguelman, destaca que antes mesmo da abolição foram criadas leis em São Paulo que incentivavam a imigração, tal como a lei $\mathrm{n}^{\circ} 36$ de 21 de fevereiro de 1881, que consignava um valor para o pagamento das passagens para os imigrantes. Portanto a abolição serviu apenas para intensificar este processo na medida em que fez com que os cafeicultores paulistas perdessem grande parte de sua força produtiva, o que os levou a realizarem a passagem do trabalho escravo para o livre. Esta transição, também explorada em termos capitalistas, promoveu incentivos à

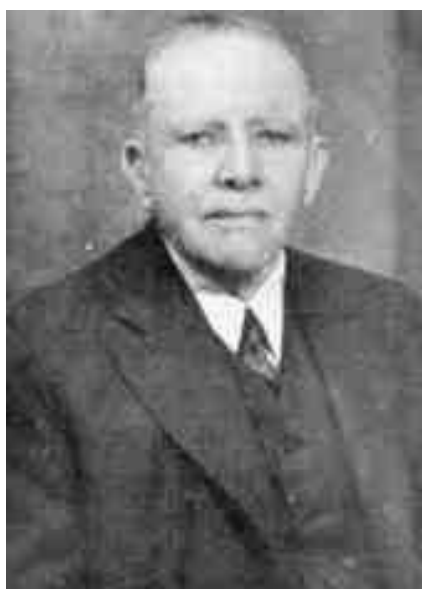

Figura 1 - Retrato Rizkallah Jorge. Fonte: Acervo da Casa da Boia. imigração, sobretudo na forma de colonato. 
Neste projeto de branqueamento da sociedade algumas etnias foram privilegiadas como mão-de-obra, especialmente os europeus. Os síriolibaneses, principalmente por sua escolha pela atividade comercial não coincidiam com os projetos que a sociedade possuía para a imigração, que era suprir a falta de mão-de-obra, logo não resolveriam, “o problema do braço agrícola, não era conveniente ao país. A imigração síria está nestas condições e é preciso dizê-lo sem reservas, pois as ideias não se misturam com interesses e conveniências 3 ”. Portanto, ao contrário do que se desejava, uma imigração rural, a imigração sírio-libanesa foi majoritariamente destinada a ambientes urbanos e formada principalmente por homens solteiros. Apesar de considerada uma imigração indesejável, diversos sírios libaneses vieram para a capital paulista e para o Brasil, fazendo com que nos anos 2000 uma pesquisa concluísse que havia aproximadamente 1 milhão de descendentes no Estado de São Paulo (Revista Veja São Paulo, 5 fev. 2003) e 10 milhões no Brasil (Revista da Folha, 23 out. 2001).

Dessa forma, fica clara a necessidade de produções acadêmicas que contribuam para o estudo do impacto destes imigrantes e que mostrem aspectos da cultura “árabe”, que possuí uma enorme circularidade cultural com a cultura brasileira, algo que possibilitou que a maioria dos imigrantes que vieram para o Brasil escolhessem por permanecer aqui.

O artigo pretende analisar a afirmação no espaço de um imigrante sírio-libanês e a consolidação de seu poder simbólico. Trata-se de Rizkallah Jorge Tahan, que em sua trajetória, tanto profissional quanto pessoal, atuou intensamente no mercado imobiliário, no ramo da

\footnotetext{
${ }^{3}$ AMARÍLIO JÚNIOR. As vantagens da immigraçãosyria no Brasil. Rio de Janeiro: Estab. Artes Gráficas, 1935, p.39.
} 
Cadernos de Clio, Curitiba, n. ${ }^{\circ}$ 4, 2013

construção civil salubre e higiênica e desempenhou uma série de atividades de urbanização na capital paulista. Portanto, o artigo visa entender suas formas de viver na cidade e suas redes sociais, enxergando o homem que construiu um papel "positivo" junto às comunidades que frequentou. Posto isto, convém frisar que o recorte temporal desta pesquisa abarcou os anos de 1895, data de seu estabelecimento no Brasil, mediante sua chegada a Santos, até o ano de sua morte, em 1949, em São Paulo.

Comecemos conhecendo a trajetória de Rizkallah na capital e os aspectos que propiciaram com que este pudesse deixar diversas marcas na cidade.

Compreendendo Rizkallah Jorge Tahan:sua história de vida e a formação de sua identidade

Como tantos imigrantes, Rizkallah Jorge também migrou para São Paulo buscando melhorar sua vida. Ele almejava que sua vinda ao Brasil propiciasse uma melhora de condições sociais para sua família, já que era o arrimo desta. Porém não foi apenas a precária condição econômica que impulsionou a vinda de sírio-libaneses ao Brasil. Alguns fatores políticos e religiosos, também determinaram a saída de muitos destes homens. Durante o século XX o governo turco tomou medidas impopulares incitando que as religiões ficassem umas contra as outras, ocasionando em 1861 o massacre de muitos libaneses cristãos. Não se pode esquecer que entre estas comunidades a religião possui um papel central, estando presente nas mais variadas dimensões da vida, ultrapassando a natureza espiritual. A perseguição religiosa levou muitas famílias cristãs libanesas e sírias a 
Cadernos de Clio, Curitiba, n. ${ }^{\circ}$ 4, 2013

abandonar o Oriente e migrar. Porém, mais importante que os fatores que propulsionaram sua decisão de migrar estão os fatores que influenciaram sua vivência e permanência na capital. Sua trajetória de vida e a posição de destaque adquirida dão indícios destes fatores.

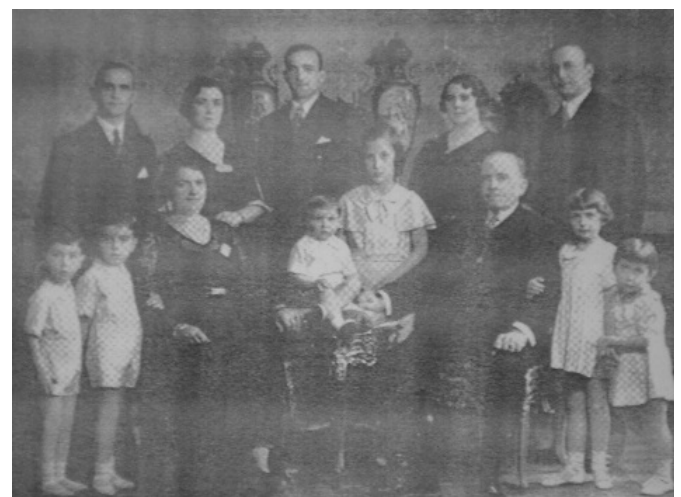

Figura 2 - Família de Rizkallah no Brasil, mostrando sua importância enquanto núcleo desta.

Fonte: Revista “Al-Kálimah”.

Nascido em 14 de maio de 1867 na cidade Aleppo, norte da atual Síria, Rizkallah Jorge perdeu sua mãe quando tinha oito meses. Seu pai tanto por ocasião do falecimento de sua esposa, quanto por um fator econômico (a grande concorrência na fundição de cobre, sua área de atuação, uma profissão muito comum na cidade de Aleppo), decidiu por se mudar para Homs, fazendo com que Rizkallah fosse criado até os cinco anos por sua avó paterna. (IN: “AL-Kálimah”) ${ }^{4}$.

Em 1882 seu pai retornou a Aleppo e se casou novamente, levando o pequeno Rizkallah para morar consigo. Esta convivência com seu pai fez com que o mesmo aprendesse a técnica da fundição de cobre, elemento decisivo para o estabelecimento de seu comércio em São Paulo.

\footnotetext{
${ }^{4}$ Biografia feita por Farés Dábague. (IN: “AL-Kálimah”) São Paulo, 25/08/1934. Dábague conta que para escrever a biografia teve como base os 15 anos de convivência com Rizkallah, período em que ficou sabendo de diversos fatos da vida deste.
} 
Após a morte de seu pai e seu casamento, em 1895, com Zakie, filha de Mardo Naccache, um parente seu, Rizkallah se tornou o núcleo de sua família em Aleppo, sendo o responsável por sua manutenção. Com seu casamento, sua situação financeira se tornou ruim e as notícias sobre o enriquecimento na América fizeram-no decidir emigrar sem avisar nenhum de seus familiares, deixando-lhes apenas um bilhete para lerem depois que já tivesse partido. Com apenas seis meses de casado tomou um vapor até Trípoli e um vapor francês com direção ao Brasil, desembarcando no Porto de Santos e seguindo viagem com seus companheiros à cidade de São Paulo (IN: “AL-Kálimah”).

Sua trajetória na capital foi bastante singular. Ao contrário da maioria dos imigrantes de mesma procedência que chegavam à cidade e se envolviam com a comercialização de tecidos e outros objetos, tornandose, assim, mascates, Rizkallah Jorge procurou uma profissão que se adequasse à atividade que exercia em sua terra natal: a fundição de cobre ${ }^{5}$. Isto mostra uma peculiaridade deste imigrante dentro do grupo de síriolibaneses que imigraram ao Brasil, pois a grande maioria destes homens

${ }^{5}$ As características da imigração de Rizkallah Jorge parecem bastante singulares, se analisadas em comparação com as características do processo migratório desta nacionalidade escritas em "Sírios e Libaneses e seu Descendentes na Sociedade Paulista”. Truzzi propõe que a decisão de migrar era tomada no seio familiar, esta se destinava a uma acumulação de capital que serviria para adquirir bens em sua terra de origem tendo assim um caráter temporário; por fim propõe que a maioria destes veio para ser mascate uma vez que é uma profissão que exige pouco investimento inicial. O caso de Rizkallah mostra que quando imigrou já era casado, portanto o padrão homens solteiros que são enviados pela família não se encaixa com seu caso e ao chegar a São Paulo este não se tornou mascate e, sim, trabalhou como funcionário em uma empresa. Com o dinheiro que acumulou neste período, não comprou propriedades em sua terra natal, mas adquiriu a Casa da Boia, trazendo, posteriormente, sua família ao Brasil., indicando possivelmente que sua migração não possuía um caráter temporário. 
eram camponeses analfabetos, já este sabia ler, escrever ${ }^{6}$ e era um artesão bem posto em sua sociedade de origem, algo que era notado dentro da comunidade aqui fixada e que foi explorado por ele como fator de distinção social e de capitalização (BOURDIEU, 1992).

Após três anos no Brasil, Rizkallah Jorge, inaugurou seu primeiro empreendimento: uma fábrica de cobre, popularmente conhecida como Casa da Boia ${ }^{7}$, situada na Rua Florêncio de Abreu 123, considerado um dos empreendimentos mais antigos e tradicionais no comércio de metais da cidade de São Paulo (PONCIANO, 2007, p.88). Sua história na Casa da Boia será de muito sucesso. O local, existente até os dias de hoje, é um dos mais famosos exemplares do ecletismo arquitetônico na capital paulista e foi tombado pelo Conselho Municipal de Preservação do Patrimônio Histórico, Cultural e Ambiental da Cidade de São Paulo em 1992, passando por um restauro em 2008. Originalmente, o andar térreo possuía funções comerciais e o pavimento superior servia de moradia ao proprietário (TIRAPELI, 2007, p.159), que ali permaneceu entre a virada dos séculos XIX e XX.

${ }^{6}$ Existe uma outra versão quanto a esta informação no depoimento de sua nora Maria DermargosRizkallah no livro Memória da Imigração. Neste a depoente diz "Meu sogro era inteligente, não tinha estudo, não sabia nada, nem árabe nem francês, nem nada; ele veio para cá sem nada, aprendeu a falar o português depressa.” GREIBER, Betty Loeb; MALUF, Lina Saigh; MATTAR, Vera Cattini. Memórias de Imigração: libaneses e sírios em São Paulo. São Paulo: Discurso Editorial, 1998, p. 419.

${ }^{7}$ Atualmente todo o Acervo Pessoal de Rizkallah Jorge está situado neste local, em se tratando de acervo ainda não organizado segundo os procedimentos da arquivologia, não é possível informar com exatidão a localização das peças do arquivo. Informo, ainda, que o acervo poderá entrar em fase de organização em curto espaço de tempo, o que poderá auxiliar o desenvolvimento de pesquisas futuras. 
Com a inauguração de seu primeiro estabelecimento e por já estar em uma situação financeira estável Rizkallah pôde, ainda, no ano de 1898, trazer sua esposa ao Brasil e aqui teve seus três filhos, sendo: Jorge, o mais velho, Nacib, o do meio e Salim, o caçula. Em 1919,

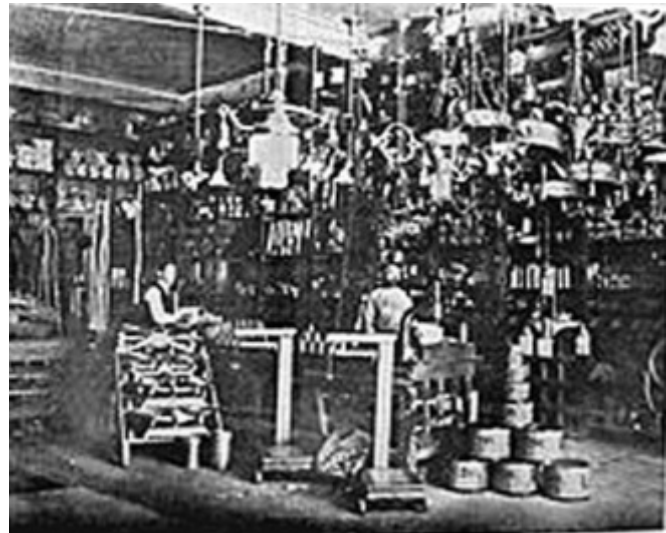

Figura 3- Funcionários Trabalhando na Casa da Boia.

Fonte: Arquivo Casa da Boia.

mudou-se com a família para a mansão, na esquina da Avenida Paulista com a Rua Bela Cintra.

Deve-se destacar que quando Rizkallah Jorge chegou à capital, o ambiente paulista já havia passado por modificações que visavam sua modernização. Estas ocorriam desde o último quarto do século XIX, procurando tornar, de fato, a capital o centro regional, econômico e comercial de São Paulo, buscando responder às novas necessidades surgidas nesta sociedade moderna. Portanto, entre fins do XIX e início do século XX uma série de projetos foi pensada para o espaço urbano paulistano, tendo por objetivo cosmopolitanizar a capital. Todas as construções encomendadas por Rizkallah estavam localizadas nessas regiões que foram alvos destes projetos, e se situavam principalmente na região central que ainda era uma das mais valorizadas na cidade de São Paulo.

O autor Benedito Lima de Toledo em “Três cidades em um Século” propõe que as mudanças que a cidade sofreu foram de tal magnitude que 
uma geração não reconhecia a cidade surgida uma geração depois. Para este autor, a cidade seria como um palimpsesto ${ }^{8}$, em que três cidades foram construídas e destruídas em um século. Em fins do XIX a cidade que existia guardava feições coloniais, com ruas estreitas e irregulares, algo que caracterizaria uma "mudy city”, porém com a chegada da ferrovia uma nova cidade surgiu e o local deixou de ser uma parada de tropeiros edificada com taipa de pilão, para virar uma cidade de tijolos, que, por fim, foi substituída pela cidade das indústrias, feita em concreto-armado, marcada pela altura.

Rizkallah Jorge soube aproveitar o momento em que florescia na capital paulista a atividade imobiliária e entre os anos 1925 e 1930, construiu pelo menos seis grandes imóveis na capital ${ }^{9}$. Estes edifícios erigidos lhe renderam uma representação social no tecido urbano da cidade, se tornando uma manifestação visual de seu poder e projetando seu nome entre seus pares. Eles mostravam que ele, mesmo tendo chegado a São Paulo com recursos financeiros escassos, conseguiu atingir fortuna. Portanto, suas atividades ligadas ao ramo da construção, contribuíram para seu objetivo de atingir reconhecimento nas sociedades em que frequentava. Todas essas construções estavam de acordo com os estilos arquitetônicos vigentes, esmaecendo a ideia recorrente na historiografia arquitetônica de que os imigrantes procuravam construir locais que lembrassem sua

\footnotetext{
${ }^{8}$ Embora esta teoria não seja plenamente aceita na pesquisa, os marcos visuais e históricos da obra são imprescindíveis para o entendimento da cultura arquitetônico-urbanística dentro do recorte temporal.

9 Os edifícios Palacete São Jorge, Palacete Paraíso e 1928 Palacete Aleppo, na Rua Carlos de Souza Nazaré; um prédio no número 92,93, 157 na Rua Florêncio de Abreu; um prédio, no número 1003, da Rua 25 de Março.
} 
Cadernos de Clio, Curitiba, n. ${ }^{\circ}$ 4, 2013

pátria de origem por saudosismo ou necessidade de afirmação na sociedade brasileira.

Entre os anos de 1910 e 1940 foi proprietário da Garage Rouge na Rua Florêncio de Abreu, uma oficina de concertos mecânicos. Suas atividades comerciais não se esgotaram no comércio, ele também atuou importando cargas e alugando imóveis ${ }^{10}$.

Esta gama de atividades encontradas na trajetória de Rizkallah Jorge parece encontrar paralelo com a própria quantidade de comunidades estrangeiras com as quais manteve laços. Ele também contribuiu com comunidade armênia doando um terreno e dinheiro para a construção da Igreja Apostólica Armênia do Brasil, em 1938 (Folha de São Paulo, 20 de março de 1937), e novamente em 1949, uma vez que a antiga foi desapropriada pela prefeitura. No ano de 1921 ajudou a coletividade síria na construção do Hospital Sírio e contribuiu para a fundação do Clube Sírio Libanês. Doou para campanha de Solidariedade Contra a Lepra a verba necessária para a construção de um prédio destinado à obra comunitária e também o dinheiro para a construção do prédio principal do Clube Sírio, que tem seu nome gravado na fachada ${ }^{11}$. Portanto fica evidente que Rizkallah Jorge foi importante também para os círculos sociais destas comunidades. O mesmo escreve em telegrama “A melhor filantropia é aquela que é feita, em primeiro lugar, aos familiares (IN: “AL-Kálimah”. Carta de 28/06/1934)”, se referindo ao fato de preferir ajudar a seus pares.

${ }^{10}$ Recibos, contratos e notas fiscais do Acervo da Casa da Boia atestam estas atividades.

${ }^{11} \mathrm{O}$ acervo da Casa da Boia contêm recibos e cartas que se referem a estas doações. 
Essa vivência entre sírios, armênios e libaneses é explicada por sua genealogia. Nascido em Aleppo na Grande Síria, região que durante o Império Otomano compreendia as regiões do Líbano, Síria, Jordânia, Israel e territórios da Palestina, Rizkallah Jorge era de família de origem armênia por isto o sobrenome Tahan. Esta origem tanto sírio-libanesa quanto armênia fez com que este transitasse no Brasil entre as duas

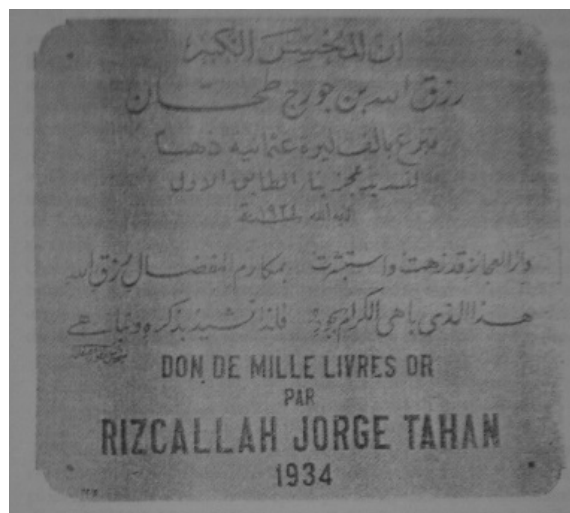

Figura 4- Placa em homenagem a doação a Revista “Al- Kálimah”.

\section{Fonte: Revista “Al- Kálimah”.} comunidades $^{12}$.

Percebeu-se que Rizkalah continuou conectado com a sua pátria devido alguns acontecimentos, dentre eles, seu retorno a Aleppo, em 1911, para uma viagem, quando doou o sino existente na Igreja dos Quarenta Mártires e a verba para a construção de uma torre; e novamente em 1921 quando foi realizado o casamento de seu filho Jorge com Maria Demargos, que lhe deram cinco netos. O imigrante também se ligava à região por meio da benemerência doando em 1916 ao prefeito de Aleppo, Bei Gháleb Katraghássi 2500 francos, para que este distribuísse comida à população da cidade, que estava sofrendo com a Primeira Grande Guerra.

${ }^{12}$ Isto pode ser percebido em suas benemerências que iam desde doações a sua cidade na Síria, quanto a construção da Igreja São Jorge para a Comunidade Armênia. 
Em 1934, doou a Associação “Al-Kálimah” mil libras otomanas e recebeu a medalha de mérito do Governo sírio.

Sua importância à pátria de origem se deu também no fato que entre os anos de 1920-1930 muitos dos imigrantes que fugiram dos massacres se hospedaram em sua casa enquanto não tinham condições de sobreviver na cidade.

Em fins da década de 20 seu filho Nagib se casou com Olga, filha de Taufik Casmie, tendo com ela dois filhos. No ano de 1928 recebeu o certificado de naturalização e realizou uma película mostrando a Casa da Boia ${ }^{13}$, sua família e suas obras, tais como o Palacete São Jorge. O filme, talvez seja uma tentativa de preservar seu legado para a comunidade em São Paulo.

Em 14 de junho de 1949 sua trajetória de sucesso na capital teve fim, o filantropo recebeu uma série de homenagens após sua morte das

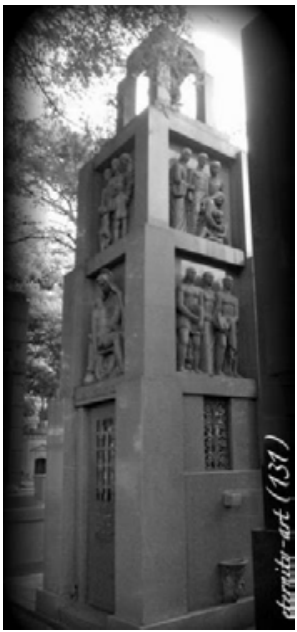

Figura 5 - Túmulo de Rizkallah.

Fonte: Eternity

Art Blog. diversas instituições que colaborou, entre elas, o Orfanato Lar Sírio e a Igreja São Jorge (Estado de São Paulo, 21/06/1949; 19/06/1949). Ele foi enterrado no cemitério da Consolação, sendo seu túmulo mais um monumento que perpetua seu nome e legado. O túmulo possui inscrições em árabe que remetem a sua origem e demonstram sua religiosidade, bem como esculturas que representam a cidade de São Paulo, a indústria que

${ }^{13} \mathrm{O}$ original deste documento se localiza no Acervo da Casa da Boia. 
desenvolvia na cidade, além de motivos religiosos e a imagem da Igreja São Jorge ${ }^{14}$.

\section{Seu poder simbólico e a atividade filantrópica}

A filantropia desempenhada por Rizkallah Jorge, possivelmente foi o principal fator que contribuiu para afirmá-lo dentro das comunidades que frequentou e para a sua formação como uma figura mítica.

A atividade da benemerência possui uma centralidade nas famílias sírio-libanesas, funcionando como uma espécie de elo entre estas pessoas que passaram pelo processo migratório. No local onde estas famílias se estabelecem elas criam redes de ajuda mútua e de manutenção de costumes por meio das instituições filantrópicas. Um dos exemplos para entender o papel que a filantropia tem dentro desta comunidade é

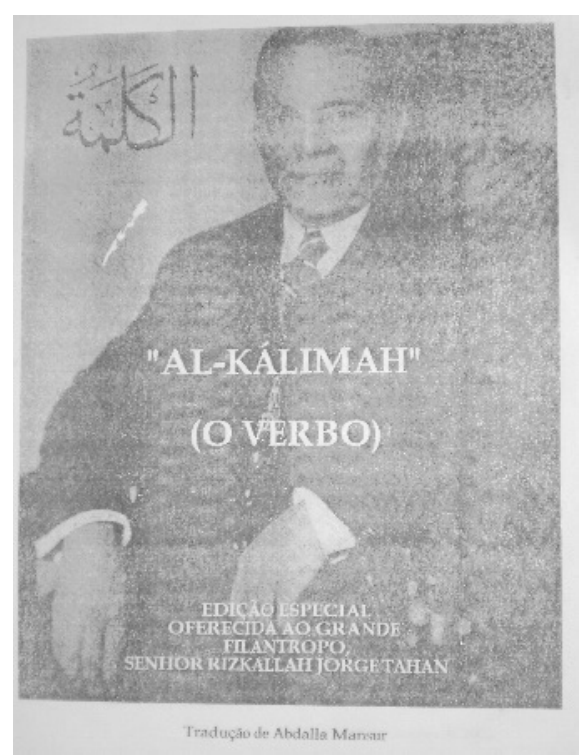

Figura 6 - Capa da Edição Especial da Revista "Al- Kálimah".

Fonte: Acervo Pessoal Casa da Boia.

o Orfanato Lar Sírio (SOUKEF, 2005), criado por uma comunidade de imigrantes vindos de Homs em 1923. O lar é mantido até os dias de hoje

\footnotetext{
14 Disponível em: http://eternity-art.blogspot.com.br/2009/12/rizkallah-jorgetahanian-arte-tumular.html Acesso em: 04/02/2013.”
} 
pela colônia sírio-libanesa de São Paulo. A história deste orfanato permite que se perceba em que grau a coletividade se une em torno de um propósito - formar um orfanato - mostrando que a história da imigração está intimamente ligada ao surgimento das instituições filantrópicas. O próprio Rizkallah Jorge Tahan foi um dos grandes colaboradores desta instituição. Pelo fato de ter realizado doações vultosas, foi lhe feita uma homenagem, batizando uma das alas do orfanato com seu nome (Estado de São Paulo 25/12/1942).

Outro episódio que ajuda a dimensionar a importância desta questão se dá em torno de uma revista contida em seu acervo pessoal. A revista “Al-Kálimah” 15 possibilita entender e interpretar o papel que a filantropia adquiriu na trajetória de Rizkallah. A revista síria é uma edição especial feita em sua homenagem, como uma forma de agradecimento por uma doação feita que possibilitou evitar sua falência. Em seu conteúdo consta toda a correspondência trocada entre ele e os redatores da revista para que a doação pudesse ser realizada. A reprodução de reportagens sobre como a doação repercutiu na região, bem como a correspondência a respeito da medalha de mérito concedida pelo Governo sírio a Rizkallah. O editor da revista também encomendou obras como poemas para homenageá-lo e uma biografia escrita, em 1934, por Fáres Dábague, presidente do Esporte Clube Sírio.

A revista mostra que por meio da benemerência, Rizkallah Jorge, foi reconhecido publicamente em sua cidade natal, recebendo uma medalha de mérito. Observa-se que por meio dos poemas encomendados pela

${ }^{15}$ Tradução de Abdallah Mansur “O Verbo”. 
homenagem da revista passou-se a existir uma espécie de adoração em torno da figura de Rizkallah. Por exemplo: “Alegra-te e regozija-te, ó Cidade de Alepo, a Branca, porque tu continuas a dar à luz a filhos devotados, que fazem subir o teu prestígio e elevam cada vez mais a tua posição (Revista “Al-Kálimah”)”.

Portanto, esta doação fez com que ele obtivesse uma posição de destaque tanto em sua comunidade natal quanto na sociedade em que vivia, pois podemos perceber que até em São Paulo a notícia de sua homenagem teve uma repercussão, tendo em vista que o presidente do Clube Sírio sentiu-se na obrigação de escrever uma biografia de Rizkallah.

Estes dois episódios de benemerência realizada por Rizkallah lhe propiciaram um poder simbólico. De acordo com as concepções de Durkheim as funções sociais exercidas pelos agentes tendem sempre a se transformar em funções políticas (BOURDIEU, 1992a, p.30). Em decorrência deste fato, os sistemas simbólicos passam a representar, também instrumentos de poder de legitimação da ordem vigente. Este poder cumpre ainda com uma função agregadora dentro de si, pois vemos que as comunidades tendem a se agregar ao redor de seus símbolos culturais.

Um dos exemplos que permite compreender o poder simbólico deste imigrante por meio de sua benemerência se dá na carta a seguir:

\section{“SR. RIZKALLAH JORGE TAHAN}

Tem uma cabeça alongada, a sua testa é larga, suas bochechas são planas, até o término do maxilar inferior e o seu queixo é bem acabado. E assim ela tem uma aparência perfeitamente proporcio- 
Cadernos de Clio, Curitiba, n. ${ }^{\circ}$ 4, 2013

nal no seu conjunto, suas feições são nítidas e a sua parte superior não é diferente, em tamanho, e inferior.

Tem dois olhos abertos com delicadeza, há em suas duas pupilas um brilho suave, que irradia mensagens de compaixão e carinho.

É como se você, ao olhar para o traçado de seu rosto e para o comprimento e a proporcionalidade que ele contém, tivesse a impressão de ver surgir na sua frente um daqueles capitalistas americanos, que foram chamados de reis, como "Ford", "Rockfeller", "Morgan" e outros. Pois, há em seu semblante muita semelhança com aqueles ricaços, dos quais nos separa o Oceano Atlântico.

Sim, o Sr. Tahan em sua aparência é americano nos seus trajes, porém é árabe em seu intimo e em seu sentimento. Se houver nele algum traço de moralidade americana seria o de ser um daqueles americanos filantropos, que doam dinheiro, generosamente, por amor à Humanidade e que não fazem distinção entre um povo e outro ao fazerem as suas doações, mas o que lhes interessa é ajudar todo necessitado, socorrer toda pessoa atingida pela desgraça e levar adiante todo projeto beneficente ou construtivo.

Se compararmos o Sr. Rizkallah aos donos das grandes fortunas do Novo Mundo e aos seus filantropos, não estaremos sendo exagerados, pois mesmo se a sua fortuna não puder ser comparada às fortunas de Ford, Rockefeller, Morgan e outro reis da riqueza, ele é considerado um dos grandes ricaços de nosso país e dos países de imigração.

Se olharmos para a sua fortuna, em relação às fortunas dos grandes filantropos americanos, donos de bilhões, veremos que ele não é menos filantropo do que eles. 
Na sua terra natal, a Cidade Branca (Alepo), ele fez tanta caridade, que este espaço não é suficiente para enumerá-la. todavia, basta-nos dizer que ele distribuiu grandes somas de dinheiro para os necessitados e idosos, doou para a reanimação do projeto da Associação Al-Kalima (O Verbo) mil libras otomanas de ouro. Este pródigo patriota continua a dar prosseguimento às suas doações, de modo que não passa muito tempo sem que ele faça uma boa e notável obra e uma caridade generosa. Como é bom quando a riqueza está nas mãos de pessoas como este homem magnânimo. Como seria bom se os nossos ricos da Síria e dos países de imigração copiassem o seu exemplo e purificassem o seu dinheiro com um pouco de caridade, mesmo que mínima, pois a purificação traz bênção e abundância às fortunas. Que valor tem um rico que só trata de ajuntar dinheiro e não gasta nada dele em benemerência e filantropia?

Os nossos abastados devem tomar o Sr. Tahan como exemplo, pois ele graças à sua fortuna e generosidade é um motivo de orgulho para a Pátria Síria. Se pudéssemos computar tudo aquilo que ele despendeu em beneficência e construção, teríamos um acervo tal, que seria suficiente para lhe ser erguida uma estátua do mais puro ouro. No entanto o Sr. Tahan tem estátuas muito mais valiosas do que essa: são as estátuas de amor e gratidão, que estão sendo construídas para ele nos fundos dos corações das pessoas, que ficam aclamando o seu nome e mencionando, eternamente, as suas caridades e as suas mãos bondosas e generosas (Acervo Casa da Boia) ${ }^{16,}$

${ }^{16}$ Não se pode saber quem escreveu a carta localizada no Acervo da Casa da Boia, pois era um recorte sem referência. 
Nela é possível perceber tanto o prestígio quanto o poder exercido por Rizkallah dentro da comunidade que convivia. Na carta ao serem retratados aspectos físicos, por exemplo, os "olhos abertos com delicadeza que denotam compaixão” pode-se perceber como esta figura era bem quista e tratada com carinho por seus pares. A admiração também fica evidente ao se descrever as diversas obras de caridades feitas por estes e, por fim, ao ser comparado com homens como Rockfeller. Ao ser mencionado o tamanho de sua fortuna, fica claro que a comunidade em que este exerceu sua influência sabia da dimensão de seu poder tanto econômico quanto político.

O aspecto agregador do poder simbólico de Rizkallah pode ser identificado tanto no sentido de criar uma rede da comunidade em torno de suas atividades filantrópicas, quanto no fato de ter abrigado os membros recém-chegados até que pudessem se estabelecer na cidade. Isto foi importante, principalmente após os anos 20, em que muitos fugiram dos massacres ocorridos na Turquia. Michel Nercessian, em entrevista a Carlos Chirinian, relata sobre esta situação, destacando que as pessoas fugidas do massacre desembarcavam no Porto de Santos em situações precárias e portando poucos pertences. Relembra, também, um episódio:

“Um dia, um armênio já radicado em Santos soube que uma leva de conterrâneos seus havia chegado ao porto. Foi até lá, levou-os à estação ferroviária e os ajudou a embarcar para a capital. Aqui chegando, não tendo onde morar nem para onde ir, foram recebidos por Rizkallah Jorge, que os abrigou num casarão que possuía na esquina da antiga Rua Anhangabaú com a Barão Duprat. Era um 
Cadernos de Clio, Curitiba, n. ${ }^{\circ}$ 4, 2013

grande galpão de três andares, onde o benemérito abrigava as famílias. Estas, permaneciam lá por cerca de dois ou três meses, até terem condições de se mudar para outro imóvel e liberar o espaço para novas levas de imigrantes. O espaço de cada família era delimitado por cortinas.”

Outro entrevistado, o Sr. Agob Guludjian ${ }^{17}$ relata ao mesmo entrevistador "que o salão onde o Padre Gabriel Samuelian rezava missa, na Rua Florêncio de Abreu, havia sido igualmente cedido por Rizkallah Jorge”. A entrevista de sua nora Maria Demargos Rizkallah (GREIBER, 1998), também corrobora estes depoimentos:

"Meu sogro ajudou muitos os armênios que vinham; chegavam aqui, não sabiam falar, não tinham nada, não tinham dinheiro. Ele comprou uma casa grande, com muitos quartos, e a cada família que vinha dava um quarto (...) fazia tudo para eles (...). Depois, meu sogro fez uma Igreja para eles (...)”.

Portanto, identifica-se em Rizkallah uma rede, aos moldes da concepção de Oswaldo Truzzi que considera que no processo migratório mais importante que as questões estruturais, é o papel do agente e a rede criada em torno deste. Para o autor, a troca de informação, as relações de complementaridade e de entreajuda serão fundamentais para a migração sírio libanesa. Essa relação se estabelece tanto na acolhida dos recém-chegados pelos que aqui viviam, quanto, comercialmente, nas relações que se esta-

\footnotetext{
17 Disponível em: <http://www.cao.org.br/rizkallahjorge.aspx> Acesso em 04/02/2013.
} 
beleceram entre industriais e grandes comerciantes. Tanto em mecanismos de facilidade de crédito, de fornecimento e de entre favorecimento, este apoio mútuo foi um elemento importante para as atividades econômicas desta colônia (TRUZZI, 2000, p.328).

Por fim, Rizkallah, frente a seus funcionários, também têm uma imagem de prestigio. As fotos contidas na parte iconográfica de

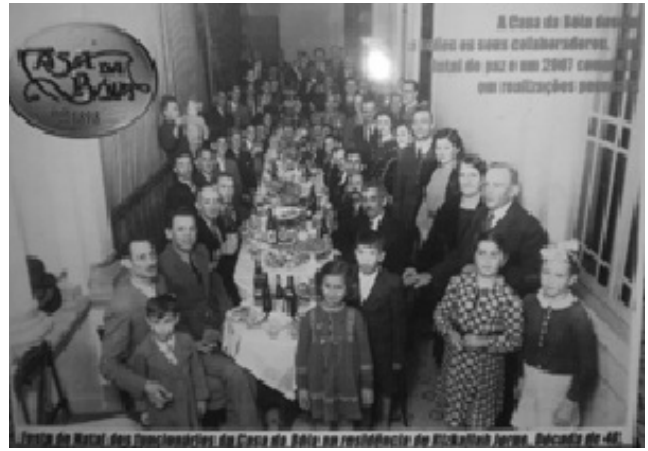

Figura 7 - Funcionários na Festa de Natal em sua residência na Avenida Paulista.

Fonte: Acervo Pessoal Casa da Boia.

seu acervo mostram fotos de jantares com seus funcionários em sua casa. O patrão os convidava para um almoço junto de seus familiares em sua casa na Avenida Paulista, indicando que este era uma pessoa muito acessível a seus funcionários. Algo que criou a imagem de um patrão exemplar junto de seus funcionários.

Tanto o poder simbólico quanto o poder político exercido de maneira quase imperceptível por Rizkallah Jorge só foram possíveis graças à urbanização pela qual passou a cidade de São Paulo. Bourdieu destaca que o sistema simbólico e político só podem existir no espaço urbano, pois a dispersão espacial da população rural dificulta as trocas econômicas e 
simbólicas e, em consequência, a tomada de consciência de interesses coletivos $^{18}$ (BOURDIEU, 1992, p.35).

Posto isto, pode-se perceber que Rizkallah Jorge Tahan desempenhou papel importante na urbanização de São Paulo, mas, igualmente, produziu, intencionalmente, eventos, fatos e representações que o destacam na história social da imigração sírio-libanesa ao Brasil.

\section{Considerações Finais}

Após analisar diversos aspectos que permearam a vida de Rizkallah Jorge Tahan ao longo dos tópicos anteriores, se tornou evidente que seus empreendimentos, possuem, "talhados” em si, uma série de "histórias” que representam as necessidades e demandas de um determinado período. Portanto, estudar os empreendimentos de Rizkallah, significa conhecer: o momento sanitário de São Paulo, que foi imprescindível para seu sucesso com sua indústria e possibilitou seu enriquecimento; a imigração e os fatores que propiciaram sua vinda, relacionados à riqueza crescente na capital ligada ao café e à vinda de imigrantes sírio-libaneses que criaram redes de informação; e por fim, tanto as suas relações de sociabilidade, quanto de identidade, que firmou reafirmando seu o poder simbólico.

Ao partir de suas iniciativas na capital chega-se ao ator social que se envolveu com uma série de atividades que denotam o cosmopolitismo que passava a tomar conta do ambiente na virada do século XIX para o

${ }^{18}$ Apesar de não podermos elencar cargos políticos/públicos ocupados por Rizkallah, cremos ter podido fazer o elenco de situações políticas e da força aglutinadora exercidas por sua figura. 
$\mathrm{XX}$, mostrando que a mentalidade da população, as construções e usos da cidade passaram por transformações.

Rizkallah teve um papel ativo neste contexto e a pesquisa identificou sua relevância no período, algo comprovado pela repercussão que seus atos filantrópicos tiveram nos jornais e pela cobertura da imprensa a respeito de sua morte. A intensa atividade de filantropia para a comunidade paulista, para a própria Síria e a intensa atividade comercial, que pode ser vista tanto no fato de ser proprietário da Casa da Boia, quanto em alguns contratos de aluguéis ( referentes a um imóvel no Anhangabaú e a locação de uma garagem), e em cartas relativas à importação de uma carga de tabaco. Todas estas atividades fizeram com que Rizkallah mantivesse uma posição de destaque junto à comunidade que convivia.

Estes elementos ligados a sua trajetória, contribuíram para o surgimento de uma imagem mítica a seu respeito, corroborada por sua família. Os depoimentos de seus familiares são um indicativo deste fator, nos depoimentos a visão de que Rizkallah foi um homem que veio sem dinheiro e estudo, mas por meio de sua habilidade artesanal e trabalho conseguiu enriquecer, indo morar na Avenida Paulista, um dos locais de moradia das classes mais abastadas do período, é sempre repetida. Seu neto Mario Roberto Rizkallah, é quem cuida do legado do avo. Todos estes fatores mostram como o poder simbólico do imigrante foi grande dentro das comunidades em que frequentou.

\section{Referências Bibliográficas}

Beiguelman, Paula. Formação do Povo no Complexo Cafeeiro: Aspectos Políticos. São Paulo: Editora da Universidade de São Paulo, 2005. 
BOURDIEU, P. A economia das trocas simbólicas. Trad. Sérgio Miceli. 3.ed. São Paulo: Perspectiva, $1992^{\mathrm{a}}$.

GREIBER, Betty Loeb; MALUF, Lina Saigh; MATTAR, Vera Cattini. Memórias de Imigração: libaneses e sírios em São Paulo. São Paulo: Discurso Editorial, 1998.

HOMEM, Maria Cecília Naclério. O palacete paulistano: e outras formas urbanas de morar da elite cafeeira, 1867-1918. São Paulo: Editora Martins Fontes, 1996.

PONCIANO, Levino. Todos os Centros da Paulicéia. São Paulo: Editora Senac São Paulo, 2007. Pág 88.

SEVCENKO, Nicolau. Orfeu extático na metrópole: São Paulo, sociedade e cultura nos frementes anos 20. São Paulo: Companhia das Letras, 2009.

SOUKEF, Antônio. Os Cinco Órfãos. São Paulo: Dialeto, 2005.

TIRAPELI, Percival. São Paulo Artes e Etnias. São Paulo: Imprensa Oficial, 2007. TOLEDO, Benedito Lima de. Álbum Iconográfico da Avenida Paulista. São Paulo: ExLibris, 1987.

Cosac \&Naify, 2004.

.São Paulo: três cidades em um século São Paulo:

TRUZZI, Oswaldo Mario Serra. Sírios e Libaneses: narrativa de história e cultura. São Paulo: CEN, 2005. 